Provided for non-commercial research and education use. Not for reproduction, distribution or commercial use.

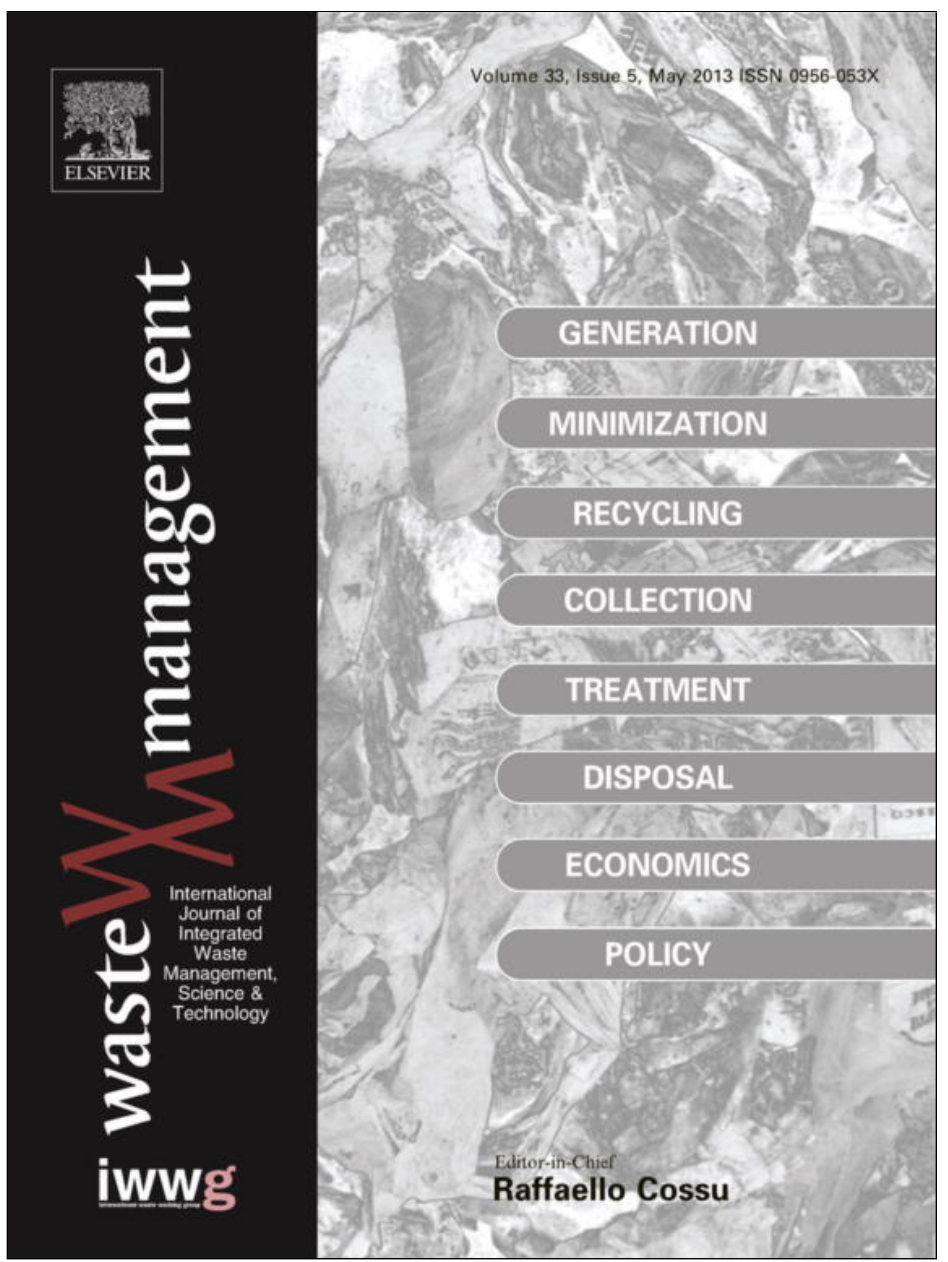

This article appeared in a journal published by Elsevier. The attached copy is furnished to the author for internal non-commercial research and education use, including for instruction at the authors institution and sharing with colleagues.

Other uses, including reproduction and distribution, or selling or licensing copies, or posting to personal, institutional or third party websites are prohibited.

In most cases authors are permitted to post their version of the article (e.g. in Word or Tex form) to their personal website or institutional repository. Authors requiring further information regarding Elsevier's archiving and manuscript policies are encouraged to visit:

http://www.elsevier.com/authorsrights 


\title{
Environmental and economic aspects of water kiosks: Case study of a medium-sized Italian town
}

\author{
Vincenzo Torretta* \\ Department of Science and High Technology, Insubria University of Varese, Via G.B. Vico, 46, I-21100 Varese, Italy
}

\section{A R T I C L E I N F O}

\section{Article history:}

Received 30 May 2012

Accepted 13 January 2013

Available online 7 March 2013

\section{Keywords:}

Bottle water

Packaging waste

Waste prevention

Drinking water

PET bottles

Water supply

\begin{abstract}
A B S T R A C T
The consumption of bottled water in Italy began in the 1970s. Since then, this usage has grown considerably, also as a result of changes in habits. The environmental impact as a result of the water production chain is very significant; it would be considered, for example, the use of plastic bottles, the consumption of oil in the production of the bottles, the emission of air from the vehicles that transport the bottles, nonrecycled plastic packaging, etc.

In this study, considering the comparison between two situations, use of bottled water and use of water kiosk (WK), an environmental and economic impact evaluation has been done. The study considered the production of a WK in a town with 9000 inhabitants, which supplies controlled, still and sparkling water, with an organoleptic quality higher than tap water coming from the aqueduct. In particular, taking into consideration the environmental aspects, specific attention was paid both to $\mathrm{CO}_{2}$ emissions and PET bottle waste reduction. The economic impact evaluation was carried out from the consumer's point of view. In order to provide a supply service that was economically sustainable, a calculation was done with the aim of determining a specific fee for the supplied water. Moreover, a comparison has been made between quality parameters achieved with the analysis of water from aqueducts with the limits established in the Italian legislation and the parameters of several Italian water brands.

The study has the aim at considering the opportunity to follow a different people's habits, closer to the concept of sustainability, reducing the environmental charge related to the realization, transport and consumption of plastic water bottles without significant reduction of the quality of the service and with convenient and interesting economic implications. In fact the results of the study show that the alternative of WKs is more efficient in economic and environmental terms respect to the use of bottled water.
\end{abstract}

(C) 2013 Elsevier Ltd. All rights reserved.

\section{Introduction}

The consumption of bottled water in Italy began in the 1970s. Since then, the consumer has had an increasing stimulus, often associated with social phenomena: over the years, drinking bottled water first became a symbol of status, and then a practice, combined with massive, growing investments on advertising campaign by multinationals which, as well as for other products, transformed the perception of water from an essential and basic drink to a source of health and even beauty. In 2010, the specific consumption of bottled water (BW) in Italy has been the highest in the world, with 200 L per capita (Legambiente, 2010) and is steadily increasing, considering that this value has tripled in just over 20 years.

Such phenomenon has had a positive economic impacts in terms of (a) number of employees as well as (b) turnover for beverage, logistics and retail marketing companies. Considering environmental aspect, Polyethylene Terephthalate (PET) water bottles

\footnotetext{
* Tel.: +39 0332 218782; fax: +390332 218779.

E-mail address: vincenzo.torretta@uninsubria.it
}

life (production, transportation and disposal) and mineral water industry impacts are negative; in particular:

- during 2008 in Italy, 350,000 t of PET was used to produce the plastic bottles necessary to contain, approximately, $1.2 \times 10^{10} \mathrm{~L}$ of mineral water (COREPLA, 2012), with a consumption of $665,000 \mathrm{t}$ of oil; the related greenhouse gases emission was approximately $910,000 \mathrm{t} \mathrm{CO}_{2} \mathrm{eq}$, calculated using the emission factor suggested by the US-EPA (2012);

- in Italy, the transportation of mineral water has a considerable effect on air pollution, because (a) the bottles travel many kilometers before arriving to consumers (Table 1 ) and (b) only $18 \%$ of the total amount of bottle freight travels by rail, one of the less pollutant means of transport (Torretta, 2009);

- in Europe, only about one third of the used plastic bottles are collected separately and forwarded for recycling (PlasticsEurope, 2012).

Regarding the management of plastic bottle waste (WPET), the disposal problem has different aspects that need to be considered. 
Table 1

Distance between springs and main Italian cities for the most diffused BW brands.

\begin{tabular}{lllllll}
\hline \multirow{2}{*}{ Brand } & \multicolumn{7}{l}{ Spring-to-city distance $(\mathrm{km})$} & & & \\
\cline { 2 - 7 } & Milan & Turin & Florence & Rome & Naples & Genoa \\
\hline Levissima & 193 & 323 & 424 & 696 & 894 & 342 \\
Vera & 251 & 411 & 244 & 516 & 715 & 373 \\
Uliveto & 264 & 423 & 266 & 538 & 736 & 401 \\
Rocchetta & 302 & 349 & 81 & 353 & 551 & 182 \\
Lilia & 491 & 609 & 196 & 191 & 390 & 432 \\
Sant'Anna & 250 & 134 & 420 & 695 & 695 & 185 \\
Lete & 252 & 102 & 390 & 662 & 860 & 184 \\
Ferrarelle & 720 & 838 & 419 & 173 & 65 & 656 \\
Panna & 288 & 406 & 36 & 324 & 523 & 263 \\
Sant'Antonio & 38 & 154 & 344 & 615 & 814 & 173 \\
San Pellegrino & 72 & 201 & 356 & 627 & 826 & 218 \\
Vitasnella & 124 & 313 & 335 & 607 & 806 & 278 \\
Mean & 270 & 355 & 293 & 500 & 656 & 307 \\
\hline
\end{tabular}

First of all, as PET is a non-biodegradable plastic (Shah et al., 2008), the disposal of post-consumer PET has huge environmental impacts (Gironi and Piemonte, 2010; Krueger et al., 2009).

PET is widely recycled as a material, making a large contribution to the recycling targets required for plastics by the EU directive 2004/12/EC. Nevertheless, a vast amount of WPET still remains unused (COREPLA, 2012). Indeed, PET is reported to be of the most abundant plastic in solid urban waste (de Mello et al., 2009).

The PET bottles obtained from household sorting are usually collected, compressed and packed by councils for transportation to recycling plants, which are operated by recycling companies. After the selection, the remaining PET bottles are shredded, cleaned, and finally turned into flakes and pellets for recycling (Al-Salem et al., 2009).The materials obtained from conventional recycling processes are PET materials customary used for nonfoods, fibers and core of multi-layer applications. Currently, the main outlet for recycled PET is the fiber market (e.g. polar fleece). Other applications include strapping, sheet and even building materials (for example, as an additive to concrete). High quality sorting and washing allows bottles to be made back into bottles for beverages and non-foods (Petcore, 2012).

For a long time, bottle-to-bottle post-consumer PET packaging materials recycling was not possible, because of the lack of knowledge about packaging polymers contamination during first use or collection. Furthermore, the decontamination efficiencies of recycling processes were in most cases unknown. Today, sophisticated decontamination processes, the so-called super-clean recycling processes, are able to decontaminate post-consumer contaminants to the concentration levels of virgin PET materials (Welle, 2011; Petcore, 2012). The output material can be used for packaging applications in which PET bottles come into direct contact to foodstuffs.

Such technologic effort brought bottle-to-bottle PET recycling to be a sound alternative to the conventional PET recycling.

Since its high calorific value (Al-Salem et al., 2009), non-recyclable PET may be used for energy recovery, which implies burning waste to produce energy in the form of heat, steam and electricity.

However, it is clear that there will be always a non-recyclable and non-recoverable WPET, maybe simply because it was not collected separately; this waste may be destined for the landfill. PBs will be crushed flat without fragmenting, occupying less space than the more rigid glass ones. In this case, the plastic residue will remain inert because it is not biodegradable (one of the reasons it is such a good choice for packaging foods is its resistance to attack by micro-organisms) and it is resistant to chemicals found in landfills. Moreover, it will not give rise to any harmful leachates (Petcore, 2012).

In order to reduce the environmental pressure of drinking water consumption, a solution could be to drink water supplied by the public aqueduct, with considerable technical, environmental and economic advantages for both the individual consumer and the whole community. With the aim of both promoting the use of drinking tap water and spreading eco-sustainable behaviors by reducing waste production at source, some Italian parish and city councils are moving towards promoting "water kiosks" or "water houses". Water kiosks (WKs) are facilities that usually have a rectangular layout, covering an area of $7-12 \mathrm{~m}^{2}$, with a height not exceeding $3 \mathrm{~m}$, that are often designed to fit into the urban landscape, with architecturally well-planned solutions. These structures are located in strategic positions and provide the public with withdrawal points of drinking water, in particular:

- water with improved organoleptic characteristics compared to tap water coming from the public aqueduct;

- still (or natural) and carbonated (or sparkling) water, either chilled or at ambient temperature.

Currently in Italy there are almost 250 WKs (about 70\% in Lombardy Region), placed in small and medium sized towns, with the exception of Milan (3 WKs) (Casa dell'Acqua, 2012).

The objective of this paper is a preliminary environmental and economic comparison between two alternative situations: the use of BW and WKs in a medium sized Italian town. After a description of the technical characteristics of the case study WK, the methodological approach is introduced. The environmental comparison is based on $\mathrm{CO}_{2}$ emissions due to the production and consumption of the same volume of drinking water, while the economic one is done on the basis of the costs for the consumer. The paper also includes a comparison between quality parameters of various aqueduct waters and BWs, also considering Italian law limits.

\section{Materials and methods}

\subsection{Case study}

The case study considers a WK situated in a town of about 9000 inhabitants in Northern Italy and its results performed during 2011 (Lura Ambiente Spa, 2012). The supplied water volume and the costs for the consumer are listed in Table 6 .

The WK has a rectangular layout $(3.30 \times 3.00)$, height $2.50 \mathrm{~m}$, and has three external walls equipped with dispensers for drinking water: two for sparkling water and one for still; the fourth wall contains the access door for WK equipment check and maintenance. Water kiosk water (WKW) is supplied by the public aqueduct.The system diagram of the WK is shown in Fig. 1 (Ciuta et al., 2012).

The sampling line from the aqueduct consists of a pressure regulator, which has a pressure valve, whose function is to maintain a constant, low water pressure within the system. Aqueduct water flows through two types of filters in order to improve its quality. The activated carbon filters remove the suspended substances and chlorine, reducing the presence of any by-products (resulting from the chlorination) and other types of micro-pollutants (up to $0.5 \mu \mathrm{m}$ ); they are changed every $5 \mathrm{~m}^{3}$ of treated water;

A battery of UV filters provide a quick, safe and economic method for disinfecting water. UV lamps are replaced whenever they stop working (max estimation, twice a year for the 3 lines).

Each water line is equipped with a flow meter in order to quantify the amount of drained water.

The outgoing still water is sent to the dispenser for the distribution of "normal water", and the water allocated for "cold sparkling water" undergoes a process of chilling and carbonation. A pump, located within the chiller, draws the water from the tank of the 
ice bank and pumps it into the recirculation pipe. The continuous flow of water allows maintaining a low temperature in the line that connects the cooler to the delivery points. The unit is connected to a $\mathrm{CO}_{2}$ cylinder (which adds a dose of $5-7 \mathrm{~g} \mathrm{CO}_{2} \mathrm{~L}^{-1}$ water to produce sparkling water). WK has five cylinders $(30 \mathrm{~kg} \mathrm{CO} 2$ each), three installed in line 1 and two in line 2. At this point, also the carbonated water reaches the line for distribution to the delivery points, passing through a flow meter and the UV filter.

Every night, the pipes undergo a cycle of sanitization to prevent bacterial regrowth with a stabilized solution based both on hydrogen and silver peroxides $\left(\mathrm{H}_{2} \mathrm{O}_{2}\right.$ and $\left.\mathrm{Ag}_{2} \mathrm{O}\right)$ and repeated washings using aqueduct water until the cleaning solution is no longer detected by the test strips. The WK is equipped with a remote control system which communicates failures, sudden problems and data useful to replace filters and gas cylinders.

\subsection{Methodological approach}

The methodological approach entails both a simplified environmental and economic assessment.

The comparison was made between two situations: the consumption of BW and the direct supply of water at the WK. Considering a drinking water consumption of $1.5 \mathrm{~L} \mathrm{~d}^{-1}$ per capita, the water supplied by the WK satisfies the demand of about 3390 inhabitants. Therefore, assuming that an average Northern-Italy family is statistically composed of 2.29 persons (ISTAT, 2011), the number of families that uses WKW is about 1480.

Before the above mentioned assessments, a short discussion about water quality of WKS and BW has been carried out comparing the same water quality parameters of both aqueduct and spring (bottled) waters, also considering respective limits established in the Italian legislation (Ministerial Decree 31/2001 and Ordinance $29 / 12 / 2003$ of the Minister of health, which is the implementation of 2003/40/EC Directive regarding natural mineral waters).
The environmental assessment focuses, above all, on the $\mathrm{CO}_{2}$ emissions into the atmosphere.

BW assessment considers both PET bottles production and BW transportation. $\mathrm{BW} \mathrm{CO}_{2}$ emissions from spring to market evaluation was done assuming that:

- the whole quantity of packaging for BW is PET (with an average unit weight of $30 \mathrm{~g}$; EFBW, 2012);

- the corresponding quantity of BW is transported by road by the means of Euro IV lorries with a $17.3 \mathrm{t}$ maximum payload (EUJRC, 2012);

- the number of 1.5 L BW transported per route is about 10,000;

- the estimated average distance between spring and market is about $270 \mathrm{~km}$; it was determined by considering the distance between the most popular Italian brands springs (or production sites) and the considered town, near to Milan (Table 1).

Annual $\mathrm{CO}_{2}$ emissions due to $\mathrm{BW}$ transport from the supermarket to the final user $\left(E_{\mathrm{CO} 2 \mathrm{BW}}\right.$, in $\left.\mathrm{kg} \mathrm{CO}_{2} \mathrm{y}^{-1}\right)$ has been estimated considering the following formula:

$E_{\mathrm{CO} 2 \mathrm{BW}}=\left(2 L_{\mathrm{Mh}} f_{s \mathrm{BW}} 365\right) F_{d \mathrm{BW}} n_{f} P_{\mathrm{CO} 2}$

where $L_{M h}$ is the average distance between the market and the final user house (in $\mathrm{km}$ ), $f_{s \text { BW }}$ is the BW supply frequency (in $\mathrm{d}^{-1}$ ), $F_{d \text { BW }}$ is a coefficient, ranging from 0 to 1 , which takes into account how the route is specific for the purchase, $n_{f}$ is the number of equivalent families who use WKW and $P_{\mathrm{CO} 2}$ is the car $\mathrm{CO}_{2}$ emissions per $\mathrm{km}$.

The considerable local variability prevents also considering the impacts and the emissions due to the disposal of the bottles.

The evaluation of $\mathrm{WKW} \mathrm{CO}_{2}$ emissions from groundwater to WK was carried out assuming that:

- groundwater is withdrawn from $100 \mathrm{~m}$ below the ground level;

- pumping station efficiency is about 0.5;

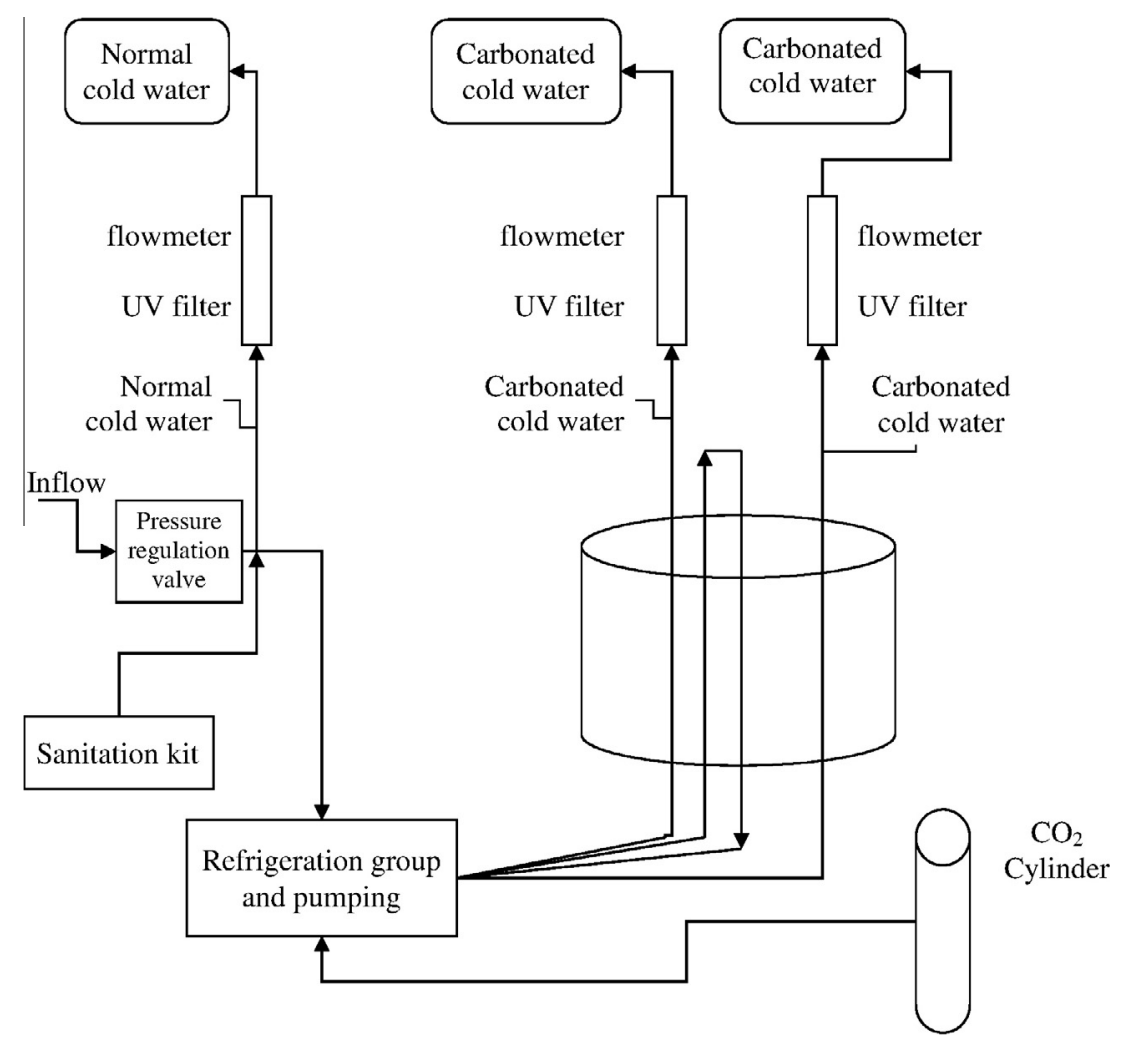

Fig. 1. Scheme of the plant. 
- water supply losses are about $30 \%$ of the pumped water (CoNViRI, 2011).

Annual $\mathrm{CO}_{2}$ emissions due to WKW transport from the WK to the final user $\left(E_{\mathrm{CO} 2} \mathrm{wKW}\right.$, in $\left.\mathrm{kg} \mathrm{CO}_{2} \mathrm{y}^{-1}\right)$ has been estimated considering the following formula:

$E_{\mathrm{CO} 2 \text { wKw }}=\left(2 L_{W K h} f_{s \text { WKW }} 365\right) F_{d \text { wKw }} n_{f} P_{\mathrm{CO} 2}$

where $L_{W K h}$ is the average distance between the market and the final user house (in km), $f_{s W K W}$ is the WKW supply frequency (in $\mathrm{d}^{-1}$ ) and $F_{d \text { WKW }}$ is a coefficient, ranging from 0 to 1 , which takes into account how the route is specific for the purchase. $f_{s \text { WKW }}$ takes into account health issues due to unknown information about disinfection status of WK users' bottles.

Estimated values, conversion factors and other data used for environmental assessment are reported in Table 2.

The economic assessment focuses on costs for the consumer and compares the:

- average cost of BW, still and carbonated, with reference to the results of a survey carried out by the author in large retailers and shopping malls in the area where the WK is located (Table 6);

- cost of WKW delivered to the consumers by the case study WK, considering the balance between the water costs and the maintenance ones.

Savings have been evaluated on consumers (single inhabitant and average family) using parameters listed in Table 2 and data listed in Table 6.

\section{Results and discussion}

\subsection{Water quality aspects}

Table 3 compares the water quality parameter limits contained in Italian law with the results of water analyses taken from three different water supply systems in Northern (Cermenate, in the Province of Como), Central (Rome) and Southern (Apulia) Italy.

Table 4 compares the parameters listed on the labels of some well-known water brands on the market with those defined Italian legislation.

Considering the physical and chemical composition, the BW quality generally can be defined as good and normally better than tap water supplied by the public aqueduct. For various and obvious reasons, the water distributed by public aqueducts achieves a good level of quality, but cannot guarantee the same quality level of spring BW (Cidu et al., 2011).
Two considerations must be made. The first is that the variability of the chemical-physical characteristics and of the overall quality of BW is very high, going from good to absolutely excellent (Temporelli and Cassinelli, 2010). The second is that the water distributed by the public aqueducts is controlled and, although the levels of quality guaranteed are lower than those of BW, the service provided is generally good and safe (Table 1 ) (Niccolucci et al., 2011).

\subsection{Environmental aspects}

Considering $\mathrm{CO}_{2}$ emissions, Table 5 shows that an equivalent 1.5 L BW has an environmental impact about five times higher than WKW. The difference mainly stands in the emissions due to PET bottle production, which are the $56 \%$ of the total amount. Another relevant contribution is the spring-to-market BW transportation (17\%), while the final step of transport (from the delivery point to house) is of the same order of magnitude for both BW and WKW; such aspect is strongly influenced by WKW frequency of supply $\left(f_{s \text { wK }}\right)$, which is limited to $0.50 \mathrm{~d}^{-1}$ for sanitary reasons.

Considering the assumptions regarding the potential consumption of oil for PET bottle production, Table 5 shows a saving of $1,237,0671.5 \mathrm{~L}$ plastic bottles (the most diffused bottle capacity volume), with a subsequent saving of PET, oil and waste (about $10.95 \mathrm{~kg}$ PET inhab ${ }^{-1} \mathrm{y}^{-1}$ ). Another important aspect relates to the lack of any need to transport the water (with positive consequences on suburban traffic), except the aqueduct water supply, since the use of the public dispensers ensures the availability of "quasi-zero km".

From the environmental point of view, one negative aspect that certainly constitutes a great problem is the management of used filters. In terms of maintenance costs, this expense is incorporated in the single item "maintenance costs", however, it is not always clear whether there is a process of regeneration or disposal involved. It should, however, be emphasized that, irrespective of the economic costs for regenerating or disposing of the used filters, the cost to the environment may be significant.

\subsection{Economic aspects}

The environmental benefits are not always sufficient to convince consumers to change their habits and customs. At this point, one powerful incentive may be the potential cost savings.

Table 6 shows the annual amount of water supplied by the kiosk: $50.1 \%$ of it is carbonated.

Clearly there is a very significant economic saving for consumers: an average family who drinks still WKW can save up to $339 € \mathrm{y}^{-1}$.

Table 2

$\mathrm{CO}_{2}$ emissions conversion factors, means of transport average fuel consumptions and estimated parameters used in the environmental assessment.

\begin{tabular}{|c|c|c|c|c|}
\hline Issue & Description/symbol & Unit & Value & References \\
\hline $\mathrm{CO}_{2}$ emissions conversion factors & $\begin{array}{l}\text { PET bottles production } \\
\text { EURO IV lorry (max payload: } 17.3 \mathrm{t}) \\
\text { Medium car }\left(P_{\mathrm{CO} 2}\right) \\
\text { Electric energy }\end{array}$ & $\begin{array}{l}\mathrm{kgCO}_{2} \mathrm{~kg}^{-1} \mathrm{PET} \\
\mathrm{kgCO}_{2} \mathrm{~kg}^{-1} \mathrm{~km}^{-1} \\
\mathrm{kgCO}_{2} \mathrm{~km}^{-1} \\
\mathrm{kgCO}_{2} \mathrm{~kW} \mathrm{~h}^{-1}\end{array}$ & $\begin{array}{l}2.6 \\
5.852 \mathrm{E}-05 \\
0.200023 \\
0.52114\end{array}$ & $\begin{array}{l}\text { US-EPA (2012) } \\
\text { EC-JRC (2012) } \\
\text { DECC-DEFRA (2011) } \\
\text { DECC-DEFRA (2011) }\end{array}$ \\
\hline Means of transport fuel consumption & $\begin{array}{l}\text { Diesel EURO IV lorry (max payload: } 17.3 \mathrm{t} \text { ) } \\
\text { Equivalent diesel medium car }\end{array}$ & $\begin{array}{l}\mathrm{L} \mathrm{kg}^{-1} \mathrm{~km}^{-1} \\
\mathrm{~L} \mathrm{~km}^{-1}\end{array}$ & $\begin{array}{l}2.474 \mathrm{E}-05 \\
7.835 \mathrm{E}-02\end{array}$ & $\begin{array}{l}\text { EC-JRC (2012) } \\
\text { DECC-DEFRA (2011) }\end{array}$ \\
\hline Estimated parameters & $\begin{array}{l}L_{M h} \\
L_{W K h} \\
f_{s \mathrm{BW}} \\
f_{s \mathrm{WKW}} \\
F_{d \mathrm{BW}} \\
F_{d \mathrm{WKW}} \\
n_{f}\end{array}$ & $\begin{array}{l}\mathrm{km} \\
\mathrm{km} \\
\mathrm{d}^{-1} \\
\mathrm{~d}^{-1} \\
- \\
- \\
\text { Inhab family }{ }^{-1}\end{array}$ & $\begin{array}{l}3.000 \\
0.500 \\
0.14 \\
0.50 \\
0.50 \\
0.50 \\
2.29\end{array}$ & $\begin{array}{l}\text { Estimated by the author for a small Italian town } \\
\text { ISTAT (2011) }\end{array}$ \\
\hline
\end{tabular}


Table 3

Comparison between Italian legislation limits and characteristics of three tap water supplied by public aqueducts.

\begin{tabular}{|c|c|c|c|c|c|}
\hline Parameter & Unit & Legislation limits & $\begin{array}{l}\text { Cermenate aqueduct } \\
\text { (Lura Ambiente Spa, 2012) }\end{array}$ & $\begin{array}{l}\text { Rome aqueduct } \\
\text { (Acea Spa, 2012) }\end{array}$ & $\begin{array}{l}\text { Apulia aqueduct } \\
\text { (Acquedotto Pugliese, 2012) }\end{array}$ \\
\hline Escherichia coli & $\mathrm{cfu} / 100 \mathrm{~mL}$ & 0 & 0 & 0 & 0 \\
\hline Enterococcus & $\mathrm{cfu} / 100 \mathrm{~mL}$ & 0 & 0 & 0 & 0 \\
\hline Coliforms at $37^{\circ} \mathrm{C}$ & $\mathrm{cfu} / 100 \mathrm{~mL}$ & 0 & 0 & 0 & 0 \\
\hline Conductivity & $\mu \mathrm{S} \mathrm{cm} \mathrm{cm}^{-1}$ & 2500 & 445 & 546 & - \\
\hline $\mathrm{pH}$ & - & $6.5-9.5$ & 7.6 & 7.5 & 7.9 \\
\hline Temperature & ${ }^{\circ} \mathrm{C}$ & Not expected & 12.9 & & 14.0 \\
\hline Total dissolved solids at $180^{\circ} \mathrm{C}$ & $\mathrm{mg} \mathrm{L}^{-1}$ & 1500 & 289 & 390 & 287 \\
\hline Total hardness & ${ }^{\circ} \mathrm{F}$ & $15-50$ & 21.5 & 32.0 & 20.0 \\
\hline Calcium & $\operatorname{mgCa~L} L^{-1}$ & Not expected & 27.5 & 98.0 & - \\
\hline Magnesium & $\mathrm{mgMg} \mathrm{L}^{-1}$ & Not expected & 7.3 & 19.0 & - \\
\hline Chloride & $\mathrm{mgCl} \mathrm{L}^{-1}$ & 250 & 24.0 & 6.5 & 29.6 \\
\hline Sulfate & $\mathrm{mgSO}_{4} \mathrm{~L}^{-1}$ & 250 & 24.7 & 15.0 & - \\
\hline Iron & $\mu \mathrm{gFe} \mathrm{L}^{-1}$ & 200 & 17 & 5 & - \\
\hline Ammonia & $\mathrm{mgNH}_{4} \mathrm{~L}^{-1}$ & 0.50 & $<0.25$ & - & - \\
\hline Nitrite & $\mathrm{mgNO}_{2} \mathrm{~L}^{-1}$ & 0.50 & $<0.06$ & - & - \\
\hline Nitrate & $\mathrm{mgNO}_{3} \mathrm{~L}^{-1}$ & 50.0 & 25.8 & 3.5 & 4.4 \\
\hline Potassium & $\mathrm{mgK} \mathrm{L}^{-1}$ & Not expected & 1.1 & 3.0 & - \\
\hline Bicarbonates & $\mathrm{mgHCO}_{3} \mathrm{~L}^{-1}$ & Not expected & 169 & - & - \\
\hline Silice & $\mathrm{mgSiO}_{2} \mathrm{~L}^{-1}$ & Not expected & 8.5 & - & - \\
\hline Sodium & $\mathrm{mgNa} \mathrm{L}^{-1}$ & 200 & 12.8 & 5.5 & - \\
\hline Arsenic & $\mu \mathrm{gAs} \mathrm{L}^{-1}$ & 10 & - & - & - \\
\hline
\end{tabular}

- : Not available.

Table 4

Comparison between Italian legislation limits and characteristics of still waters reported on bottle labels of four brands.

\begin{tabular}{|c|c|c|c|c|c|c|}
\hline Parameter & Unit & Legislation limits & Sant'Anna & Lurisia & San Benedetto & Lilia \\
\hline Escherichia coli & $\mathrm{cfu} / 100 \mathrm{~mL}$ & 0 & 0 & 0 & 0 & 0 \\
\hline Enterococcus & $\mathrm{cfu} / 100 \mathrm{~mL}$ & 0 & 0 & 0 & 0 & 0 \\
\hline Coliforms at $37^{\circ} \mathrm{C}$ & $\mathrm{cfu} / 100 \mathrm{~mL}$ & 0 & 0 & 0 & 0 & 0 \\
\hline Conductivity & $\mu \mathrm{S} \mathrm{cm}^{-1}$ & No limits & 21.7 & 31.0 & 41.5 & 46.8 \\
\hline $\mathrm{pH}$ & - & No limits & 6.50 & 6.20 & 7.42 & 6.33 \\
\hline Temperature & ${ }^{\circ} \mathrm{C}$ & No limits & 7.3 & - & 15.4 & 17.8 \\
\hline Total dissolved solids at $180^{\circ} \mathrm{C}$ & $\mathrm{mg} \mathrm{L}^{-1}$ & No limits & 22.3 & 34.8 & 272.0 & 383.0 \\
\hline Total hardness & ${ }^{\circ} \mathrm{F}$ & No limits & 0.6 & $<1.0$ & - & - \\
\hline Calcium & $\mathrm{mgCa} \mathrm{L}^{-1}$ & No limits & 1.6 & - & 48.6 & 33.9 \\
\hline Magnesium & $\mathrm{mgMg} \mathrm{L}^{-1}$ & No limits & - & 0.3 & 28.2 & 10.5 \\
\hline Chloride & $\mathrm{mgCl} \mathrm{L}^{-1}$ & No limits & - & - & 2.4 & - \\
\hline Sulfate & $\mathrm{mgSO}_{4} \mathrm{~L}^{-1}$ & No limits & 3.4 & - & 4.1 & - \\
\hline Iron & $\mu \mathrm{gFe} \mathrm{L}^{-1}$ & No limits & - & - & - & - \\
\hline Ammonia & $\mathrm{mgNH}_{4} \mathrm{~L}^{-1}$ & No limits & Not detected & - & - & - \\
\hline Nitrite & $\mathrm{mgNO}_{2} \mathrm{~L}^{-1}$ & 0.02 & Not detected & - & - & - \\
\hline Nitrate & $\mathrm{mgNO}_{3} \mathrm{~L}^{-1}$ & $45.0^{\mathrm{a}}$ & 1.0 & - & 8.5 & 6.0 \\
\hline Potassium & $\mathrm{mgK} \mathrm{L}^{-1}$ & No limits & - & 0.84 & 1.00 & 29.10 \\
\hline Bicarbonates & $\mathrm{mgHCO}_{3} \mathrm{~L}^{-1}$ & No limits & 6.0 & 18.5 & - & 268 \\
\hline Silice & $\mathrm{mgSiO}_{2} \mathrm{~L}^{-1}$ & No limits & 10.1 & 12.8 & 15.2 & - \\
\hline Sodium & $\mathrm{mgNa} \mathrm{L}^{-1}$ & Not expected & 1.9 & 2.5 & 5.8 & - \\
\hline Arsenic & $\mu \mathrm{gAs} \mathrm{L^{-1 }}$ & 10 & - & - & - & - \\
\hline
\end{tabular}

- : Not available.

a The limit for water to childhood is $10 \mathrm{mg} \mathrm{L}^{-1}$.

Table 5

Environmental balance: annual $\mathrm{CO}_{2}$ emissions.

\begin{tabular}{llll}
\hline BW & & WKW \\
\cline { 2 - 3 } Item & $\mathrm{CO}_{2}$ emissions $\left(\mathrm{kg} \mathrm{CO}_{2} \mathrm{y}^{-1}\right)$ & Item \\
\hline PET bottle production & 96,512 & Water withdrawal \\
Spring-to-market transport & 29,326 & WK energy consumption \\
Market-to-house transport & 46,318 & WK-to-house transport & 685 \\
Total & 172,156 & emissions $\left[\mathrm{kg} \mathrm{CO}_{2} \mathrm{y}^{-1}\right]$ \\
Total $\left(\mathrm{kg} \mathrm{CO}_{2} / 1.5 \mathrm{~L}\right.$ bottle) & 0.139 & Total & 27,019 \\
\hline
\end{tabular}

Often, local governments that use WKs for promotional purposes, do not demand any payment from customers (or minimum fee for carbonated water, as in the case study). Moreover, it is correct to make an assessment, considering the real cost to the public administration, in order to establish the fee that may be requested from the community, for providing an economically sustainable and public service. 
Table 6

Volume of water distributed at the WK, WKW vs. BW costs and economic savings based on change of habits in drinking water use.

\begin{tabular}{lclll}
\hline Supplied Water type & Volume $\left(\mathrm{m}^{3} \mathrm{y}^{-1}\right)$ & WKW cost $\left(€ \mathrm{~L}^{-1}\right)$ & Average BW cost $\left(€ \mathrm{~L}^{-1}\right)$ & Per-capita saving $\left(€ \mathrm{y}^{-1}\right)$ \\
\hline Still & 925.200 & $0.00($ free $)$ & 0.27 & 148 \\
Carbonated & 930.400 & 0.05 & 0.25 & 110 \\
Total & 1855.600 & & 251 \\
\hline
\end{tabular}

Table 7

Annual operating costs in the case study.

\begin{tabular}{|c|c|c|c|c|c|c|}
\hline Operative management & Item & Quantity & Unit & Unitary cost ( $€$ per unit) & Cost $\left(€ \mathrm{y}^{-1}\right)$ & Incidence (\%) \\
\hline \multirow[t]{3}{*}{$\mathrm{CO}_{2}$ cylinders } & $\mathrm{CO}_{2}$ supply & 6513 & $\mathrm{~kg}$ & 0.80 & 5210 & 12.2 \\
\hline & Cylinder change & 217 & - & $3.20^{\mathrm{a}}$ & 694 & 1.6 \\
\hline & $\mathrm{CO}_{2}$ injection system rental & 5 & - & 18.00 & 90 & 0.2 \\
\hline Filters & Filter replacement & 372 & - & $67.50^{\mathrm{b}}$ & 25,110 & 59.0 \\
\hline UV lamps & Lamps replacement & 6 & _ & 9.00 & 54 & 0.1 \\
\hline Electricity consumption & & 11,151 & $\mathrm{kWh}$ & $0.169^{c}$ & 1885 & 4.4 \\
\hline Maintenance & & 1 & $\mathrm{y}$ & 1200 & 1200 & 2.8 \\
\hline Automatic sanitizing & & 365 & d & 0.60 & 219 & 0.5 \\
\hline Chemical analysis & & 1 & $\mathrm{y}$ & 0.00 & 0 & 0.0 \\
\hline Depreciation installment & & 1 & $\mathrm{y}$ & 8100 & 8100 & 19.0 \\
\hline Total & & & & & 42,562 & 100.0 \\
\hline
\end{tabular}

a Including charges and ADR contribution.

Including disposal and regeneration.

c Including fixed costs.

An annual operating cost analysis of the case study WK has been carried out.

The $\mathrm{CO}_{2}$ cylinders, filters and UV lamps replacing costs are deduced by annual WK functioning report and from replacement frequencies (see Section 2.1). The automatic sanitizing cycle cost considers the dosed volume of reagents. WK electricity consumption costs, including fixed fees, has been made reading Electric company invoices.

The maintenance cost assessment is the most critical. In fact, all the other instruments (switchboxes, pressure pipes, electrical boards, counters, etc.) only require minimal maintenance. So, it is plausible to assume (given the lack of a precedent), that the annual maintenance cost is of the order of $15 \%$ of the cost of the devices that most require maintenance, that is the carbonation device (about $€ 8000$ ).

The water chemical analysis cost is not taken into account, assuming that it will be absorbed into the corresponding cost of the public aqueduct service.

The last item necessary for the economic assessment is the amortization cost relating to the construction (civil works, electric and hydraulic plants, architectural solutions, urban design, aqueduct, electrical and sewage networks connection, etc.). The cost of building was about $€ 68,000$, which was shared among the following items:

- civil works (structure and lacing to supply networks): $€ 42,000$;

- hydraulic works (including regulators, carbonation devices, general equipment, filters, etc.): $€ 14,000$;

- electrical systems (including switchgears and electric board): $€ 4000$;

- other technical items (e.g. design): $€ 4000$;

- finishing operations (including wall painting and green area): $€ 4000$.

An analysis of the return on investment must also include a loan to fund the work (the repayment of the economic resources spent) at an annual rate of 3.5\%, assuming a depreciation period of $10 y$ both for the civil works and for the electromechanical equipment.
Table 7 shows the summary of the annual operating costs.

The items that require most attention are the costs related to the filters replacement (59\% of the annual operating costs) and the carbonation system (14\%). UV lamps replacement, automatic sanitizing, system maintenance and electricity consumption are less than $9 \%$ of the annual costs. The remaining $19 \%$ is due to the depreciation installment.

Therefore, considering the total amount of water supplied by the kiosk and the total annual management cost, it was obtained a specific cost of less than $0.023 € \mathrm{~L}^{-1}$ both for still and carbonated water.

In the case study, the costs were covered by introducing a price for the carbonated water(Table 6). This achieved annual revenues of about $€ 46,520$ (reduced to $€ 38,700$, after VAT)

Thus, considering the annual maintenance costs, other solutions for WK break even can be:

- establishing the same price for both carbonated and still water $\left(0.03 € \mathrm{~L}^{-1}\right)$;

- introduce a cost for still water which does not consider carbonation costs $\left(0.02 € \mathrm{~L}^{-1}\right.$ for the still water and $0.03 € \mathrm{~L}^{-1}$ for the carbonated one)

\section{Conclusions}

The paper describes an environmental and economic impact evaluation carried out on a WK situated in a Northern Italy town with 9000 inhabitants. WK supplies controlled still and sparkling water in general with a better organoleptic quality, thanks to further treatment (Casa dell'Acqua, 2012). Such water has lower quality than BW but improved quality characteristics respect to tap water.

After a running time of 1 year the estimation of environmental benefits are clear, particularly with respect to reducing (a) to about one fifth the estimated $\mathrm{CO}_{2}$ emissions (mainly related to the elimination of PET bottles production and transportation), (b) the consumption of raw materials necessary for PET bottles production and transportation. Moreover, the environmental benefits include 
the waste reduction, even if the WKs filter disposal is a problem that should be deepened.

Another important aspect was economic, with a significant yearly reduction in the cost of the drinking water supply for consumers.

Thus, considering the annual maintenance costs, the WK can break even, with different solutions. But the determination of the break-even is not the main object of the paper.

Considering both the economic aspects (WK realization and management cost vs. PET BW cost at the selling points) and the environmental impact (WKs energy consumption vs. PET bottles production, use and disposal), the work would encourage the sustainable behavior of non-bottled water consumption. For such a reason, one of the aspects to be considered is the need to change people's habits, with a view to achieving sustainable development. To this end, the spread of WKs is a solution that should be encouraged, because, by maintaining a good level of service, they will guarantee better environmental and economic performance than the established habit of stocking up plastic water bottles.

\section{Acknowledgements}

The author wishes to thank the Eng. Marina Merlino and Lura Ambiente SpA Company (Caronno Pertusella, Varese, Italy) for providing both the technical support and all the available information about the WK.

\section{References}

Acea SpA, 2012. <http://www.aceaspa.it> (accessed 2012).

Acquedotto Pugliese SpA, 2012. <www.aqp.it> (accessed 2012).

Al-Salem, S.M., Lettieri, P., Baeyens, J., 2009. Recycling and recovery routes of plastic solid waste (PSW): a review. Waste Management 29 (10), 2625-2643.

Casa dell'Acqua, 2012. <http://www.casadellacqua.com> (accessed 2012).

Cidu, R., Frau, F., Tore, P., 2011. Drinking water quality: comparing inorganic components in bottled water and Italian tap water. Journal of Food Composition and Analysis 24 (2), 184-193.
Ciuta, S., Torretta, V., Trulli, E., Apostol, T., 2012. Comparison between two cases study on water kiosks. UPB Scientific Bulletin, Series D(4) 74(4), 225-232.

Consorzio Nazionale per la Raccolta, 2012. il Riciclaggio ed il Recupero dei Rifiuti di Imballaggi in Plastica. <http://www.corepla.it> (accessed 2012).

CoNViRI (Commissione Nazionale per la Vigilanza sulle Risorse Idriche), 2011. Rapporto sullo stato dei servizi idrici - Situazione organizzativa, Investimenti, Tariffe, Criticità, Roma.

De Mello, D., Pezzin, S.H., Amico, S.C., 2009. The effect of post-consumer PET particles on the performance of flexible polyurethane foams. Polymer Testing 28 (2009), 702-708.

DECC-DEFRA (Department of Energy and Climate Change-Department of Environment, Food and Rural Affairs), 2011. 2011 Guidelines to Defra/DECC's GHG Conversion Factors for Company Reporting. <www.defra.gov.uk>.

EC-JRC (European Commission-Joint Research Centre), 2012. LCA Database. <http:// lca.jrc.ec.europa.eu/lcainfohub/datasetCategories.vm> (accessed November 2012).

EFBW (European Federation of Bottled Water), 2012. <www.efbw.eu> (accessed 2012).

Gironi, F., Piemonte, V., 2010. Life cycle assessment of polylactic acid and polyethylene terephthalate bottles for drinking water. Environmental Progress \& Sustainable Energy 30 (3), 459-468.

ISTAT (Istituto Nazionale di Statistica), 2011. Italia in cifre 2011, Rome, Italy.

Krueger, M., Kauertz, B., Detzel, A., 2009. Life cycle assessment of food packaging made of Ingeo biopolymer and PET. IFEU Report, Heidelberg, Germany.

Legambiente, 2010. Un paese in bottiglia - Il caos dei canoni di concessione, i consumi da record, e l'impatto ambientale, Rome, Italy.

Lura Ambiente SpA, 2012. <www.lura-ambiente.it> (accessed 2012).

Niccolucci, V., Botto, S., Rugani, B., Bastianoni, S., Gaggi, C., 2011. The real water consumption behind drinking water: the case of Italy. Journal of Environmental Management 92, 2611-2618.

Petcore, 2012. <http://www.petcore.org> (accessed 2012).

PlasticsEurope (Association of Plastics Manifacturers), 2012. Plastics - The Facts 2012. <http://www.petcore.org> (accessed November, 2012).

Shah, A.A., Hasan, F., Hameed, A., Ahmed, S., 2008. Biological degradation of plastics: a comprehensive review. Biotechnology Advances 26 (3), 246-265.

Temporelli, G., Cassinelli, N., 2010. L'acqua in tavola. Franco Angeli Editore, Milan, Italy.

Torretta, V., 2009. Transportation of dangerous substances: a decisional support system for risk analysis. In: Proceedings: The 2009 International Conference on Chemical, Biological \& Environmental Engineering (CB' 2009) - Singapore 9-11 October 2009.

US Environmental Protection Agency, 2012. <www.epa.gov> (accessed 2012).

Welle, F., 2011. Twenty years of PETbottle to bottle recycling-an overview. Resource, Conservation and Recycling 55 (11), 865-875. 